\title{
High Prevalence of Signs of Renal Damage Despite Normal Renal Function in a Cohort of HIV-Infected Patients: Evaluation of Associated Factors
}

\author{
Anna Bonjoch, MD, PhD, Javier Juega, MD,2 Jordi Puig,, Nuria Pérez-Alvarez,,3 Aintzane Aiestarán, ${ }^{3}$ \\ Patricia Echeverría, MD, ${ }^{1}$ Vanessa Pérez, ${ }^{2}$ Bonaventura Clotet, MD, PhD, ${ }^{1,4,5}$ \\ Ramon Romero, MD, PhD, ${ }^{2}$ Josep Bonet, MD, PhD, ${ }^{2}$ and Eugenia Negredo, MD, $\mathrm{PhD}^{1,5}$
}

\begin{abstract}
Renal disorders are an emerging problem in HIV-infected patients. We performed a cross-sectional study of the first $1000 \mathrm{HIV}$-infected patients attended at our HIV unit who agreed to participate. We determined the frequency of renal alterations and its related risk factors. Summary statistics and logistic regression were applied. The study sample comprised 970 patients with complete data. Most were white (94\%) and men (76\%). Median (IQR) age was 48 (42-53) years. Hypertension was diagnosed in 19\%, dyslipidemia in 27\%, and diabetes mellitus in 3\%. According to the Chronic Kidney Disease Epidemiology Collaboration (CKD EPI) equation, 29 patients $(3 \%)$ had an eGFR $<60 \mathrm{ml} / \mathrm{min} / 1.73 \mathrm{~m}^{2} ; 18$ of them $(62 \%)$ presented altered albumin/creatinine and protein/creatinine (UPC or UAC) ratios. Of the patients with eGFR $>60 \mathrm{~mL} / \mathrm{min}$, it was present in $293(30 \%), 38$ of whom $(7.1 \%)$ had UPC $>300 \mathrm{mg} / \mathrm{g}$. Increased risk of renal abnormalities was correlated with hypertension (OR, 1.821 [95\%CI, 1.292;2.564]; $p=0.001)$, age (OR, 1.015 [95\%CI, 1.001;1.030], per one year; $p=0.040)$, and use of tenofovir disoproxil fumarate (TDF) plus protease inhibitor (PI), (OR, 1.401 [95\%CI, 1.078;1.821]; $p=0.012)$. Current CD4 cell count was a protective factor (OR, 0.9995 [95\%CI, 0.9991;0.9999], per one cell; $p=0.035$ ). A considerable proportion of patients presented altered UPC or UAC ratios, despite having an eGFR $>60 \mathrm{~mL} / \mathrm{min}$. CD4 cell count was a protective factor; age, hypertension, and use of TDF plus PIs were risk factors for renal abnormalities. Based on our results, screen of renal abnormalities should be considered in all HIV-infected patients to detect these alterations early.
\end{abstract}

\section{Introduction}

A STRONG ASSOCIATION BETWEEN chronic kidney disease [defined as estimated glomerular filtration rate (eGFR) $<60 \mathrm{~mL} / \mathrm{min} / 1.73 \mathrm{~m}^{3}$ ] and increased risk of cardiovascular events and mortality has been reported in the general population. ${ }^{1,2}$ With respect to renal damage, defined as altered albuminuria or proteinuria, or other signs of altered urine markers, are related with an increase in distinct co-morbidities. Specifically microalbuminuria, macroalbuminuria, or proteinuria, increase both the risk of cardiovascular disease (two- to fourfold) ${ }^{3}$ and the risk of mortality, independently of renal function, hypertension, or diabetes. ${ }^{4-6}$ Consequently, it is important to detect renal damage in early stages.
Regarding the HIV-infected population, the chronic and endstage kidney diseases have diminished due to the improvement of immunological status, although renal alterations still remain as a problem. ${ }^{7,8}$ Renal chronic disease is three times more prevalent than in the general population. ${ }^{9,10}$ However, the real frequency of renal abnormalities has been reported to range from $1 \%$ to $30 \%$, depending on the characteristics of the study population (e.g., race, age, and co-morbidities) ${ }^{11-13}$ and the definition of the abnormality evaluated (e.g., chronic kidney disease or signs of renal damage, that is, presence of proteinuria, albuminuria, or other signs of altered urine markers) in the absence of altered estimated glomerular filtration rate (eGFR).

Some of the factors associated with kidney alterations in $\mathrm{HIV}$-infected patients are common to the general population,

\footnotetext{
${ }^{1}$ Unitat VIH, Fundació Lluita contra la SIDA, Servicio de Medicina Interna, and ${ }^{2}$ Servicio de Nefrología, Hospital Germans Trias i Pujol, Universitat Autònoma de Barcelona, Badalona, Barcelona, Spain.

${ }^{3}$ Statistics and Operations Research Department, Universitat Politècnica de Catalunya, Barcelona, Spain.

${ }^{4}$ IrsiCaixa Foundation, Badalona, Spain.

${ }^{5}$ Universitat de Vic-Universitat Central de Catalunya, Barcelona, Spain.
} 
including, age, arterial hypertension, diabetes, use of potentially nephrotoxic drugs, and hepatitis co-infection; however, other factors are specific to HIV infection, such as low CD4 cell count, high HIV plasma viral load, or use of some antiretroviral drugs [e.g., tenofovir disoproxil fumarate (TDF)]. ${ }^{13-15} \mathrm{As}$ is usual in several co-morbidities, age is a factor at risk to developed or worsened renal disease. ${ }^{16}$

Renal disease has several clinical manifestations, from subclinical forms of renal damage, to decreased GFR or renal failure at end stages. ${ }^{11}$ On the other hand, the relevance of renal damage in the HIV-infected population can be seen in the independent association between microalbuminuria and AIDS-related death (HR, 2.3; 95\%CI, 1.3-4.3). Furthermore, patients with proteinuria are at increased risk for non-AIDSrelated death (HR, 2.4; 95\%CI, 1.2-4.6). ${ }^{17,18}$ Finally, cardiovascular events are a frequent cause of non-AIDS mortality in this population. ${ }^{19}$

The principal aim of this study was to determine the real prevalence of kidney abnormalities and related factors in our setting by assessing a large cohort of HIV-infected patients attending a tertiary hospital in Spain for routine clinical control of HIV infection.

\section{Methods}

We performed a cross-sectional study of the first $1000 \mathrm{HIV}$ infected outpatients who attended our HIV Unit and agreed to participate. All the patients signed an informed consent document. The study was approved by the Institutional Ethics Committee of the coordinating center and the local health authorities. The study period was started at January 2011, and the last patient was included in December, 2012.

A questionnaire was prospectively completed by all the patients to obtain data on personal and family history of diabetes mellitus, dyslipidemia, hypertension, cardiovascular events, renal or liver disease, previous or current syphilis, use of potentially nephrotoxic drugs (e.g., angiotensin-converting enzyme inhibitors, angiotensin receptor blockers, cyclosporine, nonsteroidal anti-inflammatory drugs, and tacrolimus), physical exercise, and the consumption of tobacco products, alcohol, and drugs of abuse.

Demographic and HIV-related data were collected from the patient's clinical records, as follows: sex, age, risk factors for HIV infection, clinical stage, time since HIV diagnosis, time with suppressed viral load, previous and current antiretroviral treatment, time on antiretroviral treatment, time on tenofovir, time on protease inhibitors, and hepatitis coinfection. Immunologic and virological data were also recorded, including current viral load, CD4 and CD8 T-cell count, peak viral load, and nadir CD4 T-cell count.

Blood and urine samples were collected in fasting conditions. Serum creatinine and phosphate were determined. Estimated GFR was calculated using the Modification of Diet in Renal Disease equation (MDRD) and the Chronic Kidney Disease Epidemiology Collaboration (CKD EPI) equations.

Normal local reference values were as follows: eGFR, $>60 \mathrm{~mL} / \mathrm{min} / 1.73 \mathrm{~m}^{2}$; serum creatinine, $<1.20 \mathrm{mg} / \mathrm{dL}$; and serum phosphate, $2.5-4.50 \mathrm{mg} / \mathrm{dL}$. Kidney disease was defined as an eGFR $<60 \mathrm{ml} / \mathrm{min} / 1.73 \mathrm{~m}^{2}$ and graded according to the Kidney Disease Outcomes Quality Initiative (KDOQI) classification. ${ }^{20}$ Renal damage was defined as the presence of micro- or macro-albuminuria, or proteinuria, by albumin/ creatinine and protein/creatinine ratios (UAC or UPC ratios), or glucosuria, hematuria, or hipophospatemia. The normal values for UPC and UAC ratios were $<200$ and $<30 \mathrm{mg} / \mathrm{g}$, respectively. Subsequently, these ratios was categorized as $<30$, $30-300$, or $>300 \mathrm{mg} / \mathrm{g}$.

Body mass index (BMI) was calculated, and arterial blood pressure was measured three times with the patient resting. Arterial hypertension was defined as a systolic blood pressure of $\geq 140 \mathrm{mmHg}$, diastolic blood pressure of $\geq 90 \mathrm{mmHg}$, or the need for antihypertensive agents. In case of high readings, patients were followed up to confirm or rule out the diagnosis of arterial hypertension. Diabetes was defined as persistent fasting glycemia $>100 \mathrm{mg} / \mathrm{dL}$ or the need for antidiabetic agents. Dyslipidemia was defined as triglycerides $>150 \mathrm{mg} / \mathrm{dL}$, total cholesterol $>200 \mathrm{mg} / \mathrm{dL}$, LDL cholesterol $>130 \mathrm{mg} / \mathrm{dL}$, or the need for lipid-lowering drugs.

\section{Statistical analyses}

Patient characteristics were described using the mean (SD), median (IQR), and frequency (\%), as appropriate.

Univariate and multivariate logistic regression analyses were performed to evaluate risk factors that might influence renal abnormalities (alteration in eGFR or signs of renal damage).

The predictor variables used in the regression models were age, smoking, gender, diabetes mellitus, arterial hypertension, BMI, dyslipidemia, time since diagnosis of HIV, use of potentially nephrotoxic drugs, nadir and current CD4 T-cell count, months on antiretroviral treatment, type of antiretroviral agent, use of TDF and of TDF plus protease inhibitors (PIs), time on protease inhibitors, and time on TDF. Variables were included in the multivariate model in such a way as to avoid multicollinearity using a stepwise procedure.

All analyses were performed using SPSS version 15.0 (SPSS Inc., Chicago, IL, USA). All tests were two-sided, and $p$ values $<0.05$ were considered statistically significant.

\section{Results}

We offered to participate in the study to all the patients visited in our AIDS Care Unit. A total of 37 subjects refused to participate. The main reason to refuse was they did not have enough time to complete the survey. We recruited the first 1000 patients who attended the HIV Unit and accepted to participate. Of these, 30 were subsequently excluded from the analysis because of missing data. Most of the remaining 970 patients were white $(94 \%)$ and men $(76 \%)$, with a median (IQR) age of 48 (42-53) years. A history of arterial hypertension was self-reported by $9 \%$ (in the questionnaire), but was diagnosed in $19 \%$ of patients by means of repetitive measurements and subsequent clinical evaluation. Dyslipidemia was diagnosed in $27 \%$ and diabetes mellitus in $3 \%$. Treatment with antihypertensive agents was taken by $87 \mathrm{pa}-$ tients (9\%), lipid-lowering agents by 142 (4.3\%), and hypoglycemic agents by $26(2.7 \%)$ (Table 1$)$.

\section{Estimated glomerular filtration rate and classification according to KDIGO criteria}

The median (IQR) eGFR according to the CKD EPI equation was $101(89.5 ; 108.2) \mathrm{mL} / \mathrm{min}$ per $1.73 \mathrm{~m}^{2}$.

According to the $2012 \mathrm{KDIGO}$ criteria, CKD parameters were normal in 507 patients $(52.3 \%)\left(\mathrm{eGFR}>90 \mathrm{~mL} / \mathrm{min} / 1.73 \mathrm{~m}^{2}\right.$ 
Table 1. Patient Characteristics, Overall and According to Grade of Altered Proteinuria

\begin{tabular}{|c|c|c|c|c|}
\hline & $\begin{array}{c}\text { Overall } \\
\text { population } \\
\mathrm{N}=970\end{array}$ & $\begin{array}{c}U A C \text { ratio } \\
>30 m g / g^{a} \\
N=58\end{array}$ & $\begin{array}{c}\text { UPC ratio } \\
>200 \mathrm{mg} / \mathrm{g}^{\mathrm{a}} \\
\mathrm{N}=75\end{array}$ & $\begin{array}{c}\text { UAC or/and } \\
U P C \text { ratios } \\
>300 \mathrm{mg} / \mathrm{g}^{\mathrm{a}} \\
\mathrm{N}=38\end{array}$ \\
\hline Gender (male), \% & $733(75.6 \%)$ & $58(100 \%)$ & $57(76 \%)$ & $29(76.3 \%)$ \\
\hline Ethnicity (white), $n(\%)$ & $916(94.4 \%)$ & $58(100 \%)$ & $70(93.3 \%)$ & $36(94.7 \%)$ \\
\hline Age, years & $48(42 ; 53)$ & $44(40 ; 48)$ & $47.75(42 ; 53)$ & $51(47 ; 58.25)$ \\
\hline BMI, $\mathrm{kg} / \mathrm{m}^{2}$ & $23.8(21.7 ; 25.86)$ & $24.24(23.18 ; 26.04)$ & $23.81(21.72 ; 25.91)$ & $23.29(20.71 ; 26.16)$ \\
\hline Diabetes, $n(\%)$ & $35(3.6 \%)$ & 0 & $2(2.6 \%)$ & $5(13 \%)$ \\
\hline Hypertension, $n(\%)$ & $189(19.5 \%)$ & $8(14 \%)$ & $14(18.7 \%)$ & $16(42 \%)$ \\
\hline Dyslipidemia & $262(27 \%)$ & $8(14 \%)$ & $20(26.6 \%)$ & $12(31.6 \%)$ \\
\hline Smoking, $n(\%)$ & $494(51 \%)$ & $41(71 \%)$ & $38(50.6 \%)$ & $12(31.5 \%)$ \\
\hline $\begin{array}{l}\text { Hepatitis B/C co-infection, } \\
\quad n(\%)\end{array}$ & $270(27.5 \%)$ & $33(57 \%)$ & $20(26.7 \%)$ & $13(34 \%)$ \\
\hline $\begin{array}{l}\text { Potentially nephrotoxic } \\
\text { concomitant therapy, } n(\%)\end{array}$ & $115(12 \%)$ & 0 & $9(12 \%)$ & $8(21 \%)$ \\
\hline $\begin{array}{l}\text { Time since diagnosis } \\
\text { of HIV infection, years }\end{array}$ & $14.95(7.43 ; 19.74)$ & $9.51(5.28 ; 18.58)$ & $14.87(7.318 ; 19.56)$ & $16.95(13.23 ; 22.47)$ \\
\hline $\begin{array}{l}\text { Current CD4 + T-cell count, } \\
\text { cells } / \mu \mathrm{L}\end{array}$ & $567(402 ; 766.25)$ & $577(337 ; 708)$ & $576(416 ; 771)$ & $487.5(290 ; 577.5)$ \\
\hline $\begin{array}{l}\text { Nadir CD4 + T-cell count, } \\
\text { cells } / \mu \mathrm{L}\end{array}$ & $214.5(99 ; 326)$ & $274(91 ; 319)$ & $219(103 ; 327)$ & $136.5(88.25 ; 254)$ \\
\hline Suppressed viral load, $n(\%)$ & $811(83.6 \%)$ & $66(85.7 \%)$ & $63(84 \%)$ & $32(84.2 \%)$ \\
\hline $\begin{array}{l}\text { Time on ARV treatment, } \\
\text { months }\end{array}$ & $151.3(70.78 ; 192.3)$ & $90.31(13.28 ; 135.45)$ & $151.39(71.11 ; 190.68)$ & $168.25(134.05 ; 211.34)$ \\
\hline Current use of PI, $n(\%)$ & $499(51.4 \%)$ & $58(100 \%)$ & $60(80 \%)$ & $34(89.4 \%)$ \\
\hline Time on PI, months & $70.85(31.41 ; 124.8)$ & $43.56(13.28 ; 48)$ & $71.54(32.35 ; 125.72)$ & $80.97(25.75 ; 144.69)$ \\
\hline Current use of TDF, $n(\%)$ & $491(50.6 \%)$ & $19(43 \%)$ & $34(45 \%)$ & $20(52.6 \%)$ \\
\hline Time on TDF, months & $32.75(17.63 ; 49.71)$ & $23.60(19.56 ; 38.46)$ & $32.81(17.88 ; 49.81)$ & $30.51(14.59 ; 42.97)$ \\
\hline
\end{tabular}

ARV, antiretroviral; BMI, body mass index; IQR, interquartile range; n, number of patients; PI, protease inhibitors; TDF, tenofovir; UAC ratio, urine albumin creatinine ratio; UPC ratio, urine protein creatinine ratio. Data are expressed as the median (IQR) unless otherwise indicated.

${ }^{\mathrm{a}}$ Grade of UAC or UPC are irrespective to the e GFR.

with no signs of renal damage). Stage $1 \mathrm{CKD}$ was recorded in 213 patients $\left(22 \%\right.$, eGFR $>90 \mathrm{~mL} / \mathrm{min} / 1.73 \mathrm{~m}^{2}$ with signs of renal damage), stage 2 in 221 patients $(22.8 \%$, eGFR $>60-90 \mathrm{~mL} / \mathrm{min} /$ $\left.1.73 \mathrm{~m}^{2}\right)$, and stage 3 in 27 patients $(2.8 \%$, eGFR $<60 \mathrm{~mL} / \mathrm{min} /$ $\left.1.73 \mathrm{~m}^{2}\right)$. One patient $(0.1 \%)$ had stage 4 CKD (eGFR between $\left.15-30 \mathrm{~mL} / \mathrm{min} / 1.73 \mathrm{~m}^{2}\right)$, and 1 patient $(0.1 \%)$ had stage 5 disease $\left(\mathrm{eGFR}<15 \mathrm{~mL} / \mathrm{min} / 1.73 \mathrm{~m}^{2}\right.$ ) (Fig. 1).

Data were very similar for the MDRD equation: 39 patients $(4 \%)$ had an eGFR $<60 \mathrm{~mL} / \mathrm{min} / 1.73 \mathrm{~m}^{2}, 1$ patient $(0.1 \%)$ had
$<15 \mathrm{~mL} / \mathrm{min} / 1.73 \mathrm{~m}^{2}, 1$ patient $(0.1 \%)$ had $15-30 \mathrm{~mL} / \mathrm{min} /$ $1.73 \mathrm{~m}^{2}$, and 37 patients $(2.8 \%)$ had $30-60 \mathrm{~mL} / \mathrm{min} / 1.73 \mathrm{~m}^{2}$.

\section{Signs of renal damage according to eGFR}

Overall, signs of renal damage (abnormal UPC, UAC, hypophosphatemia, glucosuria, hematuria, or all), was present in 311 of the patients $(32 \%)$. With regard to the eGFR, of the 29 patients with eGFR $(\mathrm{CKD}-\mathrm{EPI})<60 \mathrm{~mL} / \mathrm{min} / 1.73 \mathrm{~m}^{2}$,

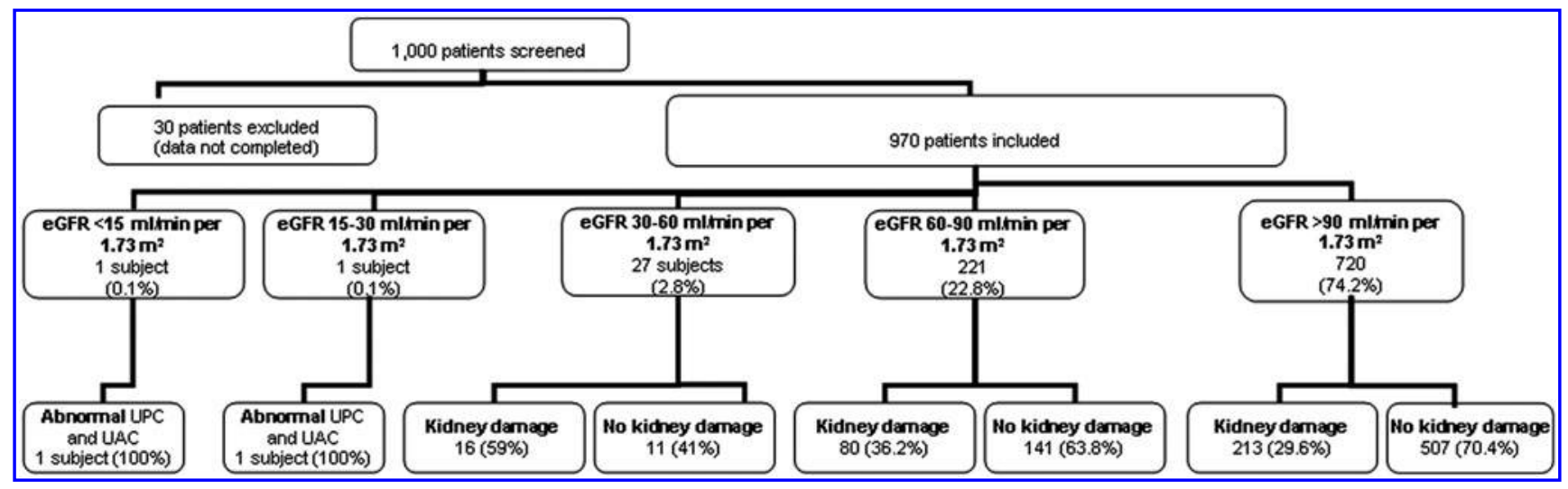

FIG. 1. Flow chart. eGFR: estimated glomerular filtration rate; kidney damage: altered albumin/creatinine and protein/creatinine ratios (UPC or UAC ratios), or presence of glucosuria, hematuria or hipophospatemia; UPC or UAC ratios: urinary proteinuria/ creatinine or albuminuria/creatinine ratios. 
Table 2. Logistic Regression Model

\begin{tabular}{|c|c|c|c|c|}
\hline & \multicolumn{2}{|l|}{ Univariate } & \multicolumn{2}{|l|}{ Multivariate } \\
\hline & Odds ratio $[95 \% \mathrm{CI}]$ & $\mathrm{p}$ Value & Odds ratio $[95 \% \mathrm{CI}]$ & $\mathrm{p}$ Value \\
\hline \multicolumn{5}{|c|}{ First model. Factors related with altered eGFR and/or abnormal UPC or UAC } \\
\hline Age (per 1 year of increase) & $1.017[1.00343 ; 1.03082]$ & 0.014 & $1.015[1.001 ; 1.030]$ & 0.040 \\
\hline Hypertension (yes vs. no) & $1.852[1.337 ; 2.564]$ & $<0.001$ & $1.821[1.292 ; 2.564]$ & 0.001 \\
\hline Hepatitis coinfection (yes vs. no) & $1.414[1.066098 ; 1.876173]$ & 0.016 & & \\
\hline BMI $<18.5$ or $>30 \mathrm{~kg} / \mathrm{m}^{2}$ (yes vs. no) & $2.169[1.373626 ; 3.436426]$ & 0.001 & $2.1277[1.335 ; 3.39]$ & 0.001 \\
\hline Current TDF use (yes vs. no) & $1.348[1.04603 ; 1.7331]$ & 0.021 & & \\
\hline Use of NRTIs (yes vs. no) & $1.335[1.030928 ; 1.730104]$ & 0.028 & & \\
\hline Use of TDF plus PIs (yes vs. no) & $1.335[1.037344 ; 1.718213]$ & 0.025 & $1.401[1.078 ; 1.8215]$ & 0.012 \\
\hline $\begin{array}{l}\text { Current CD4 cell count } \\
\text { (per increase of one cell) }\end{array}$ & $0.99945[0.999016 ; 0.99989]$ & 0.014 & $0.9995[0.9991 ; 0.9999]$ & 0.035 \\
\hline Exercise (1 or more hours per week) & $0.6238[0.48403 ; 0.80386]$ & $<0.001$ & & \\
\hline \multicolumn{5}{|c|}{ Second model. Factors related to proteinuria $>300 \mathrm{mg} / \mathrm{g}$} \\
\hline Age (per 1 year of increase) & $1.060[1.021 ; 1.101]$ & 0.002 & & \\
\hline Hypertension (yes vs. no) & $3.236[1.516 ; 6.924]$ & 0.002 & $2.91[1.339 ; 6.329]$ & 0.007 \\
\hline Diabetes mellitus (yes vs. no) & $5.242[1.697 ; 16.194]$ & 0.004 & $4.051[1.270 ; 12.919]$ & 0.018 \\
\hline $\begin{array}{l}\text { Time on antiretroviral treatment } \\
\text { (per } 1 \text { year) }\end{array}$ & $1.0002469[1.0000538 ; 1.0004399]$ & 0.012 & & \\
\hline $\begin{array}{l}\text { Nadir CD4 cell count } \\
\text { (per increase of one cell) }\end{array}$ & $0.997[0.994 ; 0.9996]$ & 0.027 & & \\
\hline Current use of Darunavir & $3.404[1.021 ; 11.351]$ & 0.046 & & \\
\hline
\end{tabular}

BMI, body mass index; eGFR, estimated glomerular filtration rate; PI, protease inhibitor; NRTIs, nucleoside reverse transcriptase inhibitors; TDF, tenofovir; UPC, urine protein/creatinine ratio; UAC, urine albumin/creatinine ratio.

$18(62 \%)$ presented any sign of renal damage. Of those with eGFR $>60 \mathrm{~mL} / \mathrm{min} / 1.73 \mathrm{~m}^{2}$, renal damage was present in 297 $(30 \%)$. Indeed in the case of a normal function (eGFR $>90$ $\mathrm{mL} / \mathrm{min} / 1.73 \mathrm{~m}^{2}$ ), signs of renal damage are present in 213 patients from $720(29.6 \%)$. Specifically, abnormal UPC or UAC ratios (UPC $>200 \mathrm{mg} / \mathrm{g}$ and/or UAC $>30 \mathrm{mg} / \mathrm{g}$ ) was detected in $75(7.8 \%)$ and $58(6 \%)$ patients, respectively.

Considering only those patients with abnormal UPC or $\mathrm{UAC}$ ratios, median values for the albumin/creatinine and protein/creatinine ratios were $54.8(38.7 ; 91.05) \mathrm{mg} / \mathrm{g}$ and 309 $(246 ; 470) \mathrm{mg} / \mathrm{g}$, respectively.

Seventy seven patients $(8 \%)$ had UAC ratio $<30$ (median [IQR], 0.9 [0.07;10]) $\mathrm{mg} / \mathrm{g}$, and 38 patients $(4 \%)$ had UPC or UAC ratios > $300(467[351 ; 887.75]) \mathrm{mg} / \mathrm{g}$.

\section{Related factors}

Logistic regression was performed in two cases: altered eGFR and/or abnormal UPC or UAC ratios and normal eGFR and in case of proteinuria $>300 \mathrm{mg} / \mathrm{g}$. The results from the univariate and multivariate analyses are summarized in Table 2.

Multivariate regression from the first model showed associations between an increased risk of abnormal UPC or UAC ratios and: hypertension [OR 1.821, (95\% IC: 1.292; 2.564), $p=0.001$ ], age [per 1 year, OR 1.015, (95\% IC $1.001 ; 1.030), p=0.040]$, BMI bellow 18 or above $30 \mathrm{~kg} / \mathrm{m}^{2}$ [OR 2.1277, (95\%IC:1.335; 3.39), $p=0.001$ ] and use of TDF plus PI, [OR 1.401, (95\%IC:1.078;1.8215), $p=0.012)]$. Current CD4 cells count [per one cell of increase, OR 0.9995, (95\% IC 0.9991;0.9999), $p=0.035$ ] was a protector factor.

In the multivariate analysis of the second model, the only variables associated with proteinuria $>300 \mathrm{mg} / \mathrm{g}$ were diabetes mellitus $(p=0.018)$ and arterial hypertension $(p=0.007)$.
Logistic regression analysis based on the MDRD equation revealed similar risk factors to the analysis based on the CKD-EPI equation (data not shown).

\section{Discussion}

The main findings of our cross-sectional study were a low percentage of patients with renal disease $(e G F R<60 \mathrm{~mL} /$ $\min / 1.73 \mathrm{~m}^{2}$ ) but, importantly, the high prevalence of signs of kidney damage, in patients with an eGFR $>60 \mathrm{~mL} / \mathrm{min} /$ $1.73 \mathrm{~m}^{2}$ and even with normal eGFR (>90 mL/min $/ 1.73 \mathrm{~m}^{2}$ ). This finding has important clinical implications for the management and control of the HIV population and led these patients as an at risk population. In addition, we also detected that arterial hypertension was an underdiagnosed risk factor in our cohort.

Consistent with findings of other HIV-infected populations in the same geographical area, advanced renal disease was infrequent in our study $(0.2 \%)$. Results from European cohorts show a prevalence of kidney disease (eGFR $<60 \mathrm{~mL} /$ $\min / 1.73 \mathrm{~m}^{2}$ ) to be $2-5 \% .{ }^{21-23}$ The relatively low median age (48 years) of our patients likely explains this finding. However, the high prevalence of patients with signs of renal damage, most of whom had an eGFR $>60 \mathrm{~mL} / \mathrm{min} / 1.73 \mathrm{~m}^{2}$ is similar to other results recently reported elsewhere, ${ }^{21}$ and, contrary, is lower than others regarding the proportion of proteinuria detected. ${ }^{23}$ Interestingly, these others signs of renal damage (no only AUC or UPC altered) could appear earlier than proteinuria in the case of renal alteration, and this is a possible explanation of the differences in the results regarding the distinct parameters evaluated. it should be take in consideration in order to early detect and manage this alterations, even when a normal eGFR is present. 
The relevance of abnormal UPC or UAC ratios is strongly associated with cardiovascular events and death in the general population, irrespective of the grade of albuminuria or proteinuria. ${ }^{5}$ A recent meta-analysis of more than 170,000 patients from 26 cohort studies concluded that patients with abnormal UPC or UAC ratios (even those with $<30 \mathrm{mg} / \mathrm{g}$ ) have a $\geq 50 \%$ greater risk of coronary heart disease than those without proteinuria. ${ }^{3}$ In the HIV-infected population, recently published articles report a correlation between microalbuminuria/proteinuria and a two-fold increased risk of both AIDS- and non-AIDS-related mortality. ${ }^{18,24}$ Consequently, HIV-infected patients should be considered a risk population and renal damage should be assessed, even in patients without other risk factors (e.g., age $>60$ years, arterial hypertension, and diabetes mellitus). ${ }^{25}$

Also relevant is the considerable number of new diagnoses of arterial hypertension in our patients. Given that hypertension is a well-established risk factor for renal damage, blood pressure should be assessed routinely in the HIV-infected population. Metabolic abnormalities such as diabetes mellitus, dyslipidemia, and arterial hypertension are progressively more frequent, and clinical monitoring of these risk factors is increasingly relevant.

Many of the factors associated with altered eGFR and proteinuria were common to those observed in the general population (such as extreme BMI or older age), supporting data from previous studies. ${ }^{26,27} \mathrm{We}$ expect an increase of renal disturbances in the next future among HIV-infected people due to their improvement of life expectancy. In fact, aging is related not only with an increased incidence of renal disease but also with an increased incidence of other comorbidities. $^{16}$

However, in contrast with findings reported elsewhere, ${ }^{13-15}$ viral load was not associated with an increase in the risk of kidney disease or proteinuria in our study, probably because of the viral suppression and preserved immune status (a protective factor) recorded in the most of our patients, which reduced the impact of HIV-related factors on renal alterations.

Tenofovir has been associated with tubular injury, ${ }^{28}$ and proximal renal tubulopathy is the most common histopathology finding; ${ }^{29}$ in contrast, altered GFR and advanced renal disease due to tenofovir seem to be infrequent. ${ }^{30,31}$ Our data showed that the use of tenofovir combined with a protease inhibitor increased the risk of kidney disease (abnormal eGFR and abnormal UPC or UAC ratios), as previously described in large cohorts. ${ }^{15,22,32}$ Higher tenofovir plasma concentration was associated with alterations in renal markers (both glomerular and tubular), ${ }^{33,34}$ and the highest plasma exposure was associated with the concomitant use of protease inhibitors. ${ }^{35}$ However, whether co-administered or not with protease inhibitors, tenofovir was not associated with proteinuria $>300 \mathrm{mg} / \mathrm{g}$ in our cohort. In fact, the most common form of TDF-related toxicity is a low level of proteinuria, ${ }^{27}$ that is usually reversible after the interruption of the drug. ${ }^{36}$

Our study has several limitations. First, its cross-sectional design could lead us to overestimate the prevalence of renal abnormalities, because of only one determination of blood and urine was collected. Second, the cross-sectional design is unable to evaluate the evolution of the renal alterations detected. Finally, since we included mainly white men, our results cannot be extrapolated to other populations. Never- theless, our study provides a reasonable picture of renal damage in the HIV-infected population in our setting.

In conclusion, severe kidney disease $(e G F R<60 \mathrm{~mL} / \mathrm{min} /$ $1.73 \mathrm{~m}^{2}$ ) was infrequent in our cohort; in contrast, signs of renal damage (mostly altered UPC or UAC ratios) were highly frequent, despite a normal eGFR. These data highlight the susceptibility of this population, and the need for early detection of renal injury, even in patients with normal renal function. In addition to HIV-related factors, factors common to the general population (e.g., age, arterial hypertension, diabetes, and extreme BMI) emerge as potentially major risk factors of renal damage.

\section{Acknowledgments}

We are grateful to Thomas O'Boyle for editorial assistance.

\section{Author Disclosure Statement}

Conflicts of interest: $\mathrm{AB}$ has received fees from VIIV, Jansen Cilag, Abbott, and Roche; PE has received personal fees from VIIV, Jansen Cilag, and Abbott; EN and BC have received personal fees from VIIV, Merck, Jansen Cilag, Abbott, Roche, and Boehringer Ingelheim. The remaining authors report no competing interests.

No financial support was received for this study.

\section{References}

1. Go AS, Chertow GM, Fan D, McCulloch CE, Hsu CY. Chronic kidney disease and the risks of death, cardiovascular events, and hospitalization. N Engl J Med 2004;351: 1296-1305.

2. Levey AS, Atkins R, Coresh J, et al. Chronic kidney disease as a global public health problem: Approaches and initiatives; A position statement from Kidney Disease Improving Global Outcomes. Kidney Int 2007;72:247-259.

3. Perkovic V, Verdon C, Ninomiya T, et al. The relationship between proteinuria and coronary risk: A systematic review and meta-analysis. PLoS Med 2008;5:e207.

4. Jha V, Garcia-Garcia G, Iseki K, et al. Chronic kidney disease: Global dimension and perspectives. Lancet 2013; 382:260-272.

5. Klausen K, Borch-Johnsen K, Feldt-Rasmussen B, et al. Very low levels of microalbuminuria are associated with increased risk of coronary heart disease and death independently of renal function, hypertension, and diabetes. Circulation 2004;110:32-35.

6. Choi AI, Li Y, Deeks SG, Grunfeld C, Volberding PA, Shlipak MG. Association between kidney function and albuminuria with cardiovascular events in HIV-infected persons. Circulation 2010;121:651-658.

7. Palella FJ, Jr., Baker RK, Moorman AC, et al. Mortality in the highly active antiretroviral therapy era: Changing causes of death and disease in the HIV outpatient study. J Acquir Immune Defic Syndr 2006;43:27-34.

8. Roling J, Schmid H, Fischereder M, Draenert R, Goebel FD. HIV-associated renal diseases and highly active antiretroviral therapy-induced nephropathy. Clin Infect Dis 2006;42:1488-1495.

9. Islam FM, Wu J, Jansson J, Wilson DP. Relative risk of renal disease among people living with HIV: A systematic review and meta-analysis. BMC Public Health 2012;12: 234. 
10. Ibrahim F, Hamzah L, Jones R, Nitsch D, Sabin C, Post FA. Baseline kidney function as predictor of mortality and kidney disease progression in HIV-positive patients. Am J Kidney Dis 2012;60:539-547.

11. Gupta SK, Eustace JA, Winston JA, et al. Guidelines for the management of chronic kidney disease in HIV-infected patients: Recommendations of the HIV Medicine Association of the Infectious Diseases Society of America. $\underline{\text { Clin }}$ Infect Dis 2005;40:1559-1585.

12. Miro JM, Cofan F, Trullas JC, et al. Renal dysfunction in the setting of HIV/AIDS. Curr HIV/AIDS Rep 2012;9:187199.

13. Winston J, Deray G, Hawkins T, Szczech L, Wyatt C, Young B. Kidney disease in patients with HIV infection and AIDS. Clin Infect Dis 2008;47:1449-1457.

14. Fernando SK, Finkelstein FO, Moore BA, Weissman S. Prevalence of chronic kidney disease in an urban HIV infected population. Am J Med Sci 2008;335:89-94.

15. Scherzer R, Estrella M, Li Y, Deeks SG, Grunfeld C, Shlipak MG. Association of tenofovir exposure with kidney disease risk in HIV infection. AIDS 2012;26:867-875.

16. Jarrett OD, Wanke CA, Ruthazer R, Bica I, Isaac R, Knox TA. Metabolic syndrome predicts all-cause mortality in persons with human immunodeficiency virus. AIDS Patient Care STDS 2013;27:266-271.

17. Szczech LA, Hoover DR, Feldman JG, et al. Association between renal disease and outcomes among HIV-infected women receiving or not receiving antiretroviral therapy. Clin Infect Dis 2004;39:1199-1206.

18. Wyatt CM, Hoover DR, Shi Q, et al. Pre-existing albuminuria predicts AIDS and non-AIDS mortality in women initiating antiretroviral therapy. Antivir Ther 2011;16:591-596.

19. French AL, Gawel SH, Hershow R, et al. Trends in mortality and causes of death among women with HIV in the United States: A 10-year study. J Acquir Immune Defic Syndr 2009;51:399-406.

20. National Kidney Foundation. KDOQI Clinical Practice Guidelines for chronic kidney disease: evaluation c, and stratification. Am J Kidney Dis 2002;39:S1-S266.

21. Calza L, Vanino E, Magistrelli E, et al. Prevalence of renal disease within an urban HIV-infected cohort in northern Italy. Clin Exp Nephrol 2014;18:104-112.

22. Mocroft A, Kirk O, Reiss P, et al. Estimated glomerular filtration rate, chronic kidney disease and antiretroviral drug use in HIV-positive patients. AIDS 2010;24:1667-1678.

23. Tordato F, Cozzi Lepri A, Cicconi P, et al. Evaluation of glomerular filtration rate in HIV-1-infected patients before and after combined antiretroviral therapy exposure. $\underline{\text { HIV }}$ Med 2011;12:4-13.

24. Wyatt CM, Hoover DR, Shi Q, et al. Microalbuminuria is associated with all-cause and AIDS mortality in women with HIV infection. J Acquir Immune Defic Syndr 2010; 55:73-77.

25. Hallan SI, Stevens P. Screening for chronic kidney disease: Which strategy? J Nephrol 2010;23:147-155.
26. Levey AS, Coresh J. Chronic kidney disease. Lancet 2012; 379:165-180.

27. Gupta SK, Smurzynski M, Franceschini N, Bosch RJ, Szczech LA, Kalayjian RC. The effects of HIV type-1 viral suppression and non-viral factors on quantitative proteinuria in the highly active antiretroviral therapy era. Antivir Ther 2009; 14:543-549.

28. Labarga P, Barreiro P, Martin-Carbonero L, et al. Kidney tubular abnormalities in the absence of impaired glomerular function in HIV patients treated with tenofovir. AIDS 2009;23:689-696.

29. Zaidan M, Lescure FX, Brocheriou I, et al. Tubulointerstitial nephropathies in HIV-infected patients over the past 15 years: A clinico-pathological study. Clin J Am Soc Nephrol 2013;8:930-938.

30. Gallant JE, Moore RD. Renal function with use of a tenofovircontaining initial antiretroviral regimen. AIDS 2009;23:19711975.

31. O’Donnell EP, Scarsi KK, Darin KM, Gerzenshtein L, Postelnick MJ, Palella FJ, Jr. Low incidence of renal impairment observed in tenofovir-treated patients. J Antimicrob Chemother 2011;66:1120-1126.

32. Goicoechea M, Liu S, Best B, et al. Greater tenofovirassociated renal function decline with protease inhibitor-based versus nonnucleoside reverse-transcriptase inhibitor-based therapy. J Infect Dis 2008;197:102-108.

33. Poizot-Martin I, Solas C, Allemand J, et al. Renal impairment in patients receiving a tenofovir-cART regimen: Impact of tenofovir trough concentration. J Acquir Immune Defic Syndr 2012;62:375-380.

34. Rodriguez-Novoa S, Labarga P, D'Avolio A, et al. Impairment in kidney tubular function in patients receiving tenofovir is associated with higher tenofovir plasma concentrations. AIDS 2010;24:1064-1066.

35. Calcagno A, Gonzalez de Requena D, Simiele M, et al. Tenofovir plasma concentrations according to companion drugs: A cross-sectional study of HIV-positive patients with normal renal function. Antimicrob Agents Chemother 2013;57:1840-1843.

36. Bonjoch A, Echeverria P, Perez-Alvarez N, et al. High rate of reversibility of renal damage in a cohort of HIV-infected patients receiving tenofovir-containing antiretroviral therapy. Antiviral Res 2012;96:65-69.

Address correspondence to:

Anna Bonjoch, $M D, P h D$

Fundació Lluita contra la SIDA

Hospital Universitari Germans Trias i Pujol

Ctra de Canyet, $s / n$

08916 Badalona

Barcelona

Spain

E-mail: abonjoch@flsida.org 